\title{
OS PRONUNCIAMENTOS DA PRESIDENTE DILMA ROUSSEFF (PT) NO DIA DO TRABALHADOR NOS ANOS DE 2014 E 2015: MEMÓRIAS E SILENCIAMENTOS NO PROCESSO DE CONSTRUÇÃO DE IMAGEM
}

Dilma Rousseff's (PT) pronouncements in the worker's day in the years of 2014 and 2015: memoirs and silences in the process of construction of image

\author{
Los pronunciamientos de la presidente Dilma Rousseff (PT) en el día del \\ trabajador en los años de 2014 y 2015: memorias y silenciamientos en el \\ proceso de construcción de imagen
}

Luiz Ademir de Oliveira Docente do Programa de Pós-Graduação em Comunicação Social (PPGCOM) da Universidade Federal de Juiz de Fora (UFJF) e do Curso de Comunicação Social Jornalismo da Universidade Federal de São João del-Rei (UFSJ). Mestre em Comunicação Social pela UFMG, mestre e doutor em Ciência Política pelo IUPERJ. luizoli@ufsj.edu.br.

Paulo Roberto Figueira Leal

Docente do Programa de Pós-Graduação em Comunicação Social (PPGCOM) da Universidade Federal de Juiz de Fora (UFJF) e da Faculdade de Comunicação (FACOM/UFJF). Mestre e Doutor em Ciência Política pelo IUPERJ. pabeto.figueira@uo.com.br.

Gustavo Fernandes Paravizo Mira Doutorando em Ciências Sociais pelo Programa de Pós-Graduação em Ciências Sociais da Universidade Federal de Juiz de Fora (UFJF). Mestre em Comunicação Social pelo PPGCOM/UFJF e Graduado em Comunicação Social - Jornalismo pela UFV. gustavoparavizo@yahoo.com.br.

\section{Resumo}

O artigo discute a relação entre capital político e visibilidade midiática a partir da análise das estratégias de comunicação da ex-presidente Dilma Rousseff (PT) em seus pronunciamentos no Dia do Trabalhador. Foram tomados como recortes o discurso feito em 2014 em Cadeia Nacional de Rádio e Televisão (CNRT) e os pronunciamentos de 2015 postados nas redes sociais. Em função da baixa popularidade da petista neste segundo momento, a fala foi veiculada apenas na internet, evitando a superexposição na mídia massiva. Com isso, o governo pretendia evitar uma possível onda de manifestações similares às ocorridas no pronunciamento em CNRT no Dia Internacional da Mulher, no dia 8 de março de 2015, quando ocorreram os primeiros "panelaços". Com base na Análise de Discurso francesa, 
busca-se compreender, em perspectiva comparativa, os mecanismos discursivos que emergiram nas falas da presidente nos dois momentos.

Palavras-chave: Dilma Rousseff. Análise do Discurso. Visibilidade Midiática.

\begin{abstract}
This article discusses the relationship between political capital and media visibility based on the analysis of the communication strategies of ex-President Dilma Rousseff (PT) in its pronouncements on Labor Day. The speeches made in 2014 on the National Radio and Television Network (CNRT) and the statements posted on social networks on 2015 were taken as cutbacks. Due to the low popularity of PT in this second moment, the speech was transmitted only on the Internet, avoiding overexposure in the mass media. As a result, the government intended to avoid a possible wave of manifestations similar to those that occurred in the CNRT statement on 2015 March 8, in the International Women's Day, when the first "panelaços" took place. Based on the French Discourse Analysis, we sought to understand, in a comparative perspective, the discursive mechanisms that emerged in the speeches of the president in the two moments.
\end{abstract}

Keywords: Dilma Rousseff. Speech Analysis. Media Visibility.

\title{
Resumen
}

El artículo discute la relación entre capital político y visibilidad mediática a partir del análisis de las estrategias de comunicación de la ex presidenta Dilma Rousseff (PT) en sus pronunciamientos en el Día del Trabajador. Se tomaron como recortes el discurso hecho en 2014 en Cadena Nacional de Radio y Televisión (CNRT) y los pronunciamientos de 2015 publicados en las redes sociales. En función de la baja popularidad de la petista en este segundo momento, el discurso fue transmitido sólo en Internet, evitando la sobreexposición en los medios masivos. Con eso, el gobierno pretendía evitar una posible ola de manifestaciones similares a las ocurridas en el pronunciamiento en CNRT en el Día Internacional de la Mujer, en 8 de marzo de 2015, cuando ocurrieron los primeros "panelazos". Con base en el análisis del discurso francesa, se busca comprender, en perspectiva comparativa, los mecanismos discursivos que emergieron en las conversaciones de la presidenta en los dos momentos.

Palabras-clave: Dilma Rousseff. Análisis del Discurso. Visibilidad Mediática.

\section{INTRODUÇÃO}

O presente artigo tem por objetivo, por meio de análise discursiva, comparar as ênfases adotadas pela então presidente Dilma Rousseff (PT) em pronunciamentos do Dia do Trabalhador em dois distintos momentos: no ano final de seu primeiro mandato, em 2014, e no primeiro ano de sua segunda gestão, em 2015, que foi interrompida em função do processo 
de impeachment. Dilma acabou tendo o seu mandato cassado pelo Senado em 31 de março de 2016 com a acusação de ter cometido irregularidades - no caso "pedaladas fiscais", ou seja, de realização de operações financeiras não previstas e autorizadas no orçamento. Mas, já em 2015, um ano após a sua reeleição, numerosas circunstâncias se alteraram em relação à popularidade da governante e às condições políticas do país, o que gerou, por exemplo, mudanças já conhecidas quanto aos meios e instrumentos de comunicação utilizados pelo governo.

Ao longo do primeiro mandato, a então presidente Dilma Rousseff (PT) utilizou a Cadeia Nacional de Rádio Televisão (CNTR) para fazer 21 pronunciamentos aos brasileiros. Seguindo uma lógica publicitária, a maior parte dos pronunciamentos foi veiculada em datas com forte apelo simbólico, como Dia da Independência e do Dia do Trabalhador. Dilma ocupou a cadeia nacional para anunciar projetos e ações de governo, para dirigir mensagens a setores e segmentos sociais específicos, para defender o governo de críticas oposicionistas e, num caso bastante particular, em função da onda de protestos conhecida como "Jornadas de Junho" de 2013, para acalmar os ânimos e responder oficialmente ao grande número de reivindicações populares desencadeadas no país naquele momento.

Em maio de 2015, no entanto, o governo escolheu uma estratégia de comunicação diferente. Depois de usar a CNRT para se pronunciar em homenagem ao Dia do Trabalhador, sucessivamente, de 2011 a 2014, a presidente decidiu se pronunciar exclusivamente via internet, fazendo uso do Blog do Planalto e das redes sociais para divulgar o discurso à classe trabalhadora. Essa opção ocorreu no momento em que Dilma estava com o seu mais baixo índice de aprovação popular desde sua chegada à Presidência. Isso se deveu, também, ao fato de que, no Dia Internacional da Mulher, dia 8 de março de 2015, Dilma chegou a fazer um pronunciamento em cadeia nacional e houve numerosos protestos pelo país, conhecidos como "panelaços".

Essa mudança de plataformas, em resposta às alterações de contexto, foi acompanhada de modificações também no conteúdo dos discursos? Que memórias discursivas (e elipses) foram acionadas em dois cenários tão diferentes, a ponto de ter sido alterada inclusive a tecnologia de comunicação utilizada? Para responder a essas questões, recorre-se ao aparato metodológico oferecido pela Análise do Discurso Francesa, na busca pela identificação dos sentidos que atravessam as enunciações feitas pela presidente nos dois momentos. 


\section{VISIBILIDADE MIDIÁTICA COMO CAPITAL POLÍTICO NO AMBIENTE CONTEMPORÂNEO}

Numa contemporaneidade profundamente marcada pela presença cotidiana e pelo alcance dos meios de comunicação de massa e das tecnologias digitais na vida de milhões de pessoas, questões políticas não podem mais ser compreendidas sem a consideração de variáveis comunicacionais. Rodrigues (1990) argumenta que a mídia passa a ocupar um espaço de centralidade no mundo moderno, funcionando como um palco em que os diversos agentes buscam obter visibilidade e legitimação diante da opinião pública e de outros campos sociais.

Nas sociedades democráticas, o poder político deriva do voto e depende diretamente da credibilidade, da boa imagem e da confiança que o ator político é capaz de inspirar no eleitor, o que coloca as mídias (sejam os já consolidados meios de comunicação de massa, sejam as novas plataformas digitais) em uma posição ainda mais central para o campo político, em função da exposição que são capazes de proporcionar ao longo das disputas por legitimação popular. Gerir com competência profissional a sua aparição na esfera pública e na mídia se torna um imperativo da política contemporânea, mesmo que existam muitas dificuldades e obstáculos para os agentes políticos na construção, distribuição e administração da sua imagem pública por meio da mídia (GOMES, 2004, p. 257).

Thompson argumenta que "antes de a mídia impressa e outras mídias serem desenvolvidas, a visibilidade dos líderes políticos dependia em grande parte de sua aparição física diante dos outros, num contexto de copresença" (THOMPSON, 2008, p. 21). Para ele, o desenvolvimento das mídias comunicacionais fez nascer assim um novo tipo de visibilidade desespacializada que possibilitou uma forma íntima de apresentação pessoal, livre das amarras da co-presença. Essas foram as condições facilitadoras para o nascimento do que podemos chamar de 'sociedade da autopromoção': uma sociedade em que se tornou possível, e até cada vez mais comum, que líderes políticos e outros indivíduos aparecessem diante de públicos distantes e desnudassem algum aspecto de si mesmos ou de sua vida pessoal. A forma distanciada e impessoal da maioria dos líderes políticos do passado foi sendo gradualmente substituída por este novo tipo de intimidade mediada, pela qual os políticos podem apresentar-se não somente como líderes, mas como seres humanos, como indivíduos comuns dirigindo-se a seus companheiros cidadãos (...) (THOMPSON, 2008, p. 24). 
Tanto as mídias controladas por empresas jornalísticas independentes quanto os meios de comunicação institucionais, sob controle direto dos atores políticos ou dos governos, desempenham papel central nas estratégias políticas contemporâneas. E hoje se discute não somente o papel dos meios de comunicação massivos, mas também a comunicação digital. "O nascimento da internet e de outras tecnologias digitais amplificou a importância das novas formas de visibilidade criadas pela mídia e, ao mesmo tempo, tornou-as mais complexas", conforme argumenta Thompson (2008, p. 23). Segundo o autor, o fluxo de conteúdo audiovisual nas redes de comunicação foi potencializado, o que possibilitou que um número maior de indivíduos criasse e disseminasse conteúdos. Desta forma, dado a natureza da rede, seria muito mais difícil controlar o fluxo de conteúdo (THOMPSON, 2008, p. 23)

Nesta nova configuração social e tecnológica, houve um processo de complexificação da gestão da visibilidade - seja para os atores políticos, seja para outros campos sociais. Numa realidade marcada pela associação dos meios tradicionais com as tecnologias digitais, tornou-se imprescindível, por exemplo, incorporar o conceito de narrativa transmidiática (JENKINS, 2009). A convergência de mídias que ocorre com a emergência da web 2.0, segundo o autor, possibilitou uma nova forma de comunicação. "Uma história transmidiática se desenrola através de múltiplos suportes midiáticos, com cada novo texto contribuindo de maneira distinta e valiosa para o todo. Na forma ideal de narrativa transmidiática, cada meio faz o que faz de melhor" (JENKINS, 2009, p. 135). Isso se aplica também ao universo da política e das campanhas eleitorais.

Aggio (2013) exemplifica a questão apontando a utilização das plataformas digitais nas campanhas eleitorais, que sobretudo no século XXI passaram a explorar questões como a interação, a participação em tempo real e a convergência de mídia. $\mathrm{O}$ autor destaca quatro pontos-chave na sua análise da internet e o seu uso em estratégias de campanhas eleitorais: (a) $\mathrm{o}$ fornecimento e informações não mediadas pelos media noticiosos - o que ficou bem evidente na campanha de 2014 no Brasil quando houve um grande fluxo de informações que circularam na Web e, inclusive, foram usadas na campanha e que não foram notícias dos grandes veículos noticiosos, principalmente as de ataque aos adversários; (b) a paridade de disputas entre campanhas de pequeno e grande porte; (c) a interatividade entre eleitores e candidatos; (d) o ativismo. Sobre as diferenças entre a campanha na Web e nos meios massivos, Aggio (2013) traça alguns pontos importantes:

A grande diferença entre a televisão, o rádio e a Internet, então, estaria na forma de interação e de participação que a última oferece. Ao passo que os dois primeiros têm objetivos 
específicos claros de construir imagens e passar com eficiência uma mensagem e prescindir de contatos diretos, interativos, a terceira proporciona uma maior aproximação da campanha ao possibilitar a troca de mensagens, produzindo um efeito de sentimento de pertença e configurando elementos de participação. Se, por um lado, os novos mecanismos de participação servem às estratégias de fidelização prescritas pelo marketing político, por outro lado há práticas que podem assegurar que a interferências e sugestões dos cidadãos de fato sejam levadas em consideração. Invariavelmente, nesta circunstância, não há possibilidade de dissociar o que seria da ordem do marketing político e o que seria da ordem de uma diferenciação do modo de fazer campanha com reflexos do incremento à democracia (AGGIO, 2013, p. 180).

Lima e Silva (2010, p. 197) apontam ainda que a 'horizontalidade dialógica' dos meios digitais se caracteriza pelo compartilhamento de informação, de arquivos digitais, de diálogos e de narrativas produzidas pelos usuários das redes sociais in loco, de forma instantânea, aberta e com instrumentos de interferência e gerência de quase todos os processos. Em termos potenciais, tais características poderiam, em tese, servir à construção de uma relação democrática mais profunda entre representantes e representados.

No que se refere à comunicação entre governos e sociedade, Duarte (2007, p. 43) reivindica um ambiente comunicacional mais equitativo, que estimule a participação ativa do cidadão na esfera política. O ideal de comunicação pública apresentado pelo autor defende a superação da visão publicitária e instrumental para que a comunicação seja vista como política pública e atenda de forma efetiva ao princípio democrático de accountability e às demandas sociais por transparência governamental.

No entanto, apesar do potencial interativo e de se poder incrementar a participação, o que seria um grande avanço para as democracias, Aggio (2013) argumenta que há baixa interatividade, principalmente com base em estudos de campanhas nos EUA e em países europeus. Ao retomar a discussão sobre os dilemas da participação política nos regimes democráticos representativos, o autor sustenta que a democracia digital também esbarra no obstáculo da criação de incentivos para que o cidadão seja efetivamente participativo.

Se os potenciais dialógicos e de adensamento democrático dos ambientes digitais nem sempre encontram evidências de realização (plena ou mesmo parcial), são numerosos os indicadores de que, tal como já ocorrera com as mídias tradicionais, também nas redes a visibilidade constitui capital político essencial para a construção de carreiras políticas bemsucedidas. Compreende-se aqui capital político, tal como Luiz Felipe Miguel, como "uma 
espécie de capital simbólico: o reconhecimento da legitimidade daquele indivíduo para agir na política" (2003, p. 121).

Uma vasta literatura, que inclui o próprio Bourdieu (1996), aponta a presença crescente da mídia como fonte de capital político (mesmo que a terminologia não seja sempre usada). De fato, a visibilidade nos meios é uma condição importante para o reconhecimento público, em qualquer área de atividade, nas sociedades contemporâneas. É possível dizer que a mídia também contribui para estruturar a própria carreira política. A hierarquização dos diferentes cargos não se deve apenas - ou mesmo prioritariamente - ao poder efetivo de cada um, mas também à visibilidade de que dispõem (MIGUEL, 2003, p. 115).

De acordo com o autor, "não é qualquer exposição na mídia que alavanca pretensões eleitorais, mas sim aquelas que contribuem para a construção de uma persona pública apropriada". E conclui que, "cada vez mais, a importância desse atalho é compreendida por indivíduos com aspirações políticas, o que leva à construção deliberada de carreiras midiáticas como etapa para uma carreira política futura” (MIGUEL, 2003, p. 131).

Diante dessa realidade de simbiose entre a comunicação e a política, atores políticos percebem a relevância de construir boa imagem, na mídia tradicional e nas redes digitais, para potencializarem seus posicionamentos estratégicos. O que os pronunciamentos feitos pela então presidente Dilma Rousseff (PT) tanto na TV (em 2014) quanto nas redes sociais (2015), tomando como base metodológica a Análise de Discurso, revelam sobre essas estratégias? Para tratar do tema, é necessário que antes se discuta o contexto político bastante conturbado que marcou o período.

\section{CONJUNTURA POLÍTICA DE 2011 A 2015 E A ABORDAGEM DISCURSIVA}

Nos primeiros anos de mandato da presidente Dilma Rousseff, o Brasil vivenciou a continuidade da política econômica implantada no governo Lula. Até meados de 2013, a presidente manteve, a exemplo de Lula, uma imagem bastante positiva, chegando a obter índices de popularidade em que $60 \%$ da população consideravam o governo bom ou ótimo, segundo pesquisas trimestrais CNI-Ibope. Mas, em junho de 2013, no terceiro ano de mandato da presidente, o Brasil foi marcado por diversas manifestações de descontentamento popular. Desencadeados a partir de reivindicações por melhorias no transporte coletivo na cidade de São Paulo, os atos de protesto se intensificaram quando teve início a Copa das Confederações da FIFA. As manifestações se espalharam por todo o país, tendo ocorrido atos em todos os 
estados da federação, com presença em 438 municípios até o dia 21 de junho. Com o crescimento da onda de protestos e com a ampliação da pauta dos manifestantes, a grande mídia, que inicialmente se colocou em posição contrária aos atos por melhorias no transporte público de São Paulo, passou a se posicionar com um viés favorável às manifestações.

Passado o mês de junho, a onda de manifestações se acalmou. Mas a imagem do governo Dilma estava abalada. Nesse curto período, a aprovação popular da presidenta caiu de $57 \%$ para $30 \%$, segundo pesquisa do Datafolha, realizada nos dias 27 e 28 de junho. Ao longo de 2014, Dilma recuperou parte da popularidade, o que foi suficiente para vencer o segundo turno contra Aécio Neves (PSDB) por pouco mais de três milhões de votos.

O início do segundo mandato trouxe grandes desafios para a presidente Dilma Rousseff. Com a economia em desaquecimento, aumento da inflação e com a imagem afetada por crises de corrupção na Petrobrás, o cenário político e econômico que se apresentou era bem distinto do que a presidente encontrou ao assumir o país em 2011. A comparação das pesquisas trimestrais realizadas em parceria pela CNI e pelo IBOPE revelou que a situação no início de 2015 foi inversa à observada no começo de 2011. Ao fim do primeiro trimestre de 2011, Dilma batia recorde de aprovação popular (73\% da população). No mesmo período de 2015, a presidente batia novo recorde, mas agora de desaprovação (também $73 \%$ da população).

Foi nesse contexto de crise de imagem profunda que o Governo Federal optou por não se pronunciar em CNRT por ocasião do Dia dos Trabalhadores de 2015. Em substituição ao pronunciamento tradicional, feito nos quatro anos do primeiro mandato, Dilma fez uso da Internet, divulgando um discurso, também em vídeo, por meio do Blog do Planalto e de redes sociais. É possível conjecturar que a estratégia foi poupar a então presidente da superexposição em um momento de crise acentuada. Tal estratégia ocorre num momento em que se começa a ter um modelo cada vez mais híbrido de consumo de mídia no Brasil. A televisão ainda se mantém hegemônica, mas o uso da internet cresce a cada ano. Pesquisa da Secretaria de Comunicação Social da Presidência da República (Secom), divulgada em 2015, mostra que $49 \%$ da população acessam a Internet, enquanto $95 \%$ da população afirmam assistir TV de forma habitual (BRASIL, 2014, p.7). Em 2016, as pesquisas sobre hábitos de consumo de mídia pararam de ser feitas. Mas observa um crescimento do uso da internet, apesar de a TV ainda ser a mídia hegemônica no país. Conforme dados da pesquisa do CONECTAí Express, divulgada pelo IBOPE Inteligência em agosto de 2017, o Facebook (86\%) é a segunda rede social mais utilizada pelos brasileiros, perde apenas para o WhatsApp 
(91\%). Em 2018, o número de usuários do Facebook chega a 127 milhões mensais, o que ultrapassa o WhatsApp, aplicativo da mesma empresa.

No entanto, mesmo com este modelo híbrido de consumo de mídia, outro fator a ser levado em conta que não foi alterado no sistema de mídia brasileiro é o alto grau de concentração e de propriedade privada. De acordo com a última pesquisa veiculada pelo Monitor de Propriedade de Mídia (MOM, sigla em inglês), organizada pela RSF - Repórteres Sem Fronteira, o Brasil apresenta um dos piores indicadores de diversidade na mídia, dentre os países em desenvolvimento. De acordo com a pesquisa, as quatro principais redes de TV do país - Globo, SBT, Record e Band - somam $71 \%$ de toda a audiência do país, e essa concentração de audiência se repete nos demais veículos. O estudo mapeou 50 veículos e redes de comunicação, sendo 11 redes de TV (aberta e por assinatura), 12 redes de rádio, 17 veículos de mídia impressa (entre jornais e revistas) e 10 portais de notícias online. Esses 50 veículos analisados pertencem a 26 grupos ou empresas de comunicação, sendo que cinco grupos ou proprietários individuais concentram mais da metade desses veículos. 9 veículos pertencem ao Grupo Globo, 5 ao Bandeirantes, 5 à família Macedo, 4 à RBS e 3 ao Grupo Folha. Esses indicadores refletem a concentração de mídia no país, o que representa um risco à liberdade de expressão e falta pluralidade da mídia brasileira, bem como, seu impacto na construção da realidade e da sociedade no país.

Deve-se ressaltar, ainda, que a crise institucional levou ao impeachment da então presidente Dilma Rousseff. Em 31 de março de 2016, depois de toda a tramitação no Congresso, iniciada em dezembro de 2015, quando o então deputado Eduardo Cunha, na época presidente da Câmara dos Congressos, acatou o pedido de impeachment e iniciou o processo, a cassação da petista foi aprovada por 61 votos favoráveis e apenas 20 contrários no Senado Federal. O então vice-presidente, Michel Temer (então no PMDB - hoje MDB), assumiu, tendo sido um dos principais articuladores do impeachment de Dilma.

Tendo em vista o contraste significativo entre o contexto político do primeiro mandato de Dilma e o que se apresentou logo no início de 2015, bem como as distinções do nível de visibilidade e do tipo de recepção proporcionado pela televisão e pela Internet, realiza-se adiante uma análise discursiva dos pronunciamentos do Dia do Trabalhador em CNRT no último ano do primeiro mandato de Dilma e do pronunciamento divulgado via Internet no $1^{\circ}$ de maio de 2015. Os dados permitiram afirmar que, além das mudanças de contexto político e de mídia utilizada, também os conteúdos das falas da presidente se alteraram? 
O artigo parte do pressuposto de que os pronunciamentos de Dilma Rousseff são peças simbólicas que guardam em si a textualidade histórica do momento político brasileiro. Não apenas em função dos acontecimentos e do cenário ideológico que se materializam nos sujeitos, mas na expressão institucionalizada que marca, na dimensão do discurso, as suas características de produção. Com todo o acesso do governo às tecnologias de leitura da opinião pública e identificação das preferências dos eleitores, a narrativa construída pela presidência diz respeito a uma tomada de posição que escancara os atavismos da política brasileira por meio de gestos de interpretação e figuras de linguagem.

Influenciados pela lógica publicitária, os discursos em CNRT geralmente ocorrem em uma data de forte significado simbólico, como Natal, Dia da Mulher, Dia da Independência. São datas carregadas de sentidos acionados para fazer parte da composição das mensagens presidenciais, como os finais de ano, empregados sobretudo para realizar balanços dos anos correntes e projeções para o futuro. No caso do Dia do Trabalhador, é utilizado para anunciar ações e programas que beneficiariam a classe, enumerar conquistas recentes e para reafirmar compromissos do governo com a valorização do trabalho, do emprego e da renda.

A partir destes prismas, são analisados os mecanismos discursivos pelos quais se operam os atos oficiais de fala da presidente Dilma Rousseff nos anos de 2014 e 2015 por meio das lentes da Análise do Discurso Francesa (AD). Concebe-se que os sentidos produzidos pela presidência guardam no seu cerne os mecanismos discursivos em que se dão as disputas política travadas no ambiente contemporâneo. Foram analisados em ambos os pronunciamentos a íntegra dos discursos mediante a transcrição das peças. Definiu-se uma categorização a partir de três eixos discursivos: 1) Construção da Imagem; 2) Ataque aos Adversários; 3) Temas Políticos.

Vale ressaltar que o discurso político também é formado por interações com processos não midiáticos que permeiam a sociedade e se modificam na medida em que se alteram as conjunturas históricas e sociais. De acordo com Orlandi (2005, p. 16), "os estudos discursivos visam pensar o sentido dimensionando no tempo e no espaço das práticas do homem, descentrando a noção de sujeito e relativizando a autonomia do objeto da linguística”. Neste âmbito, entende-se que os meios de comunicação são pensados enquanto espaço de constituição e transformação de sentidos sociais e, mais do que isso, de constituição e transformação de sujeitos do discurso, partindo-se da premissa teórica de que sujeito e sentido constituem-se mutuamente (ORLANDI, 2007). 
Para a $\mathrm{AD}$, o discurso é entendido como efeito de sentidos entre interlocutores - ou seja, ele não existe por si mesmo, mas só em um espaço entre sujeitos. Dessa forma, o discurso é a palavra em movimento, na prática de linguagem. Assim, o processo comunicativo se dá não a partir da transmissão de informação através de uma mensagem, e nem concebe a separação entre emissor e receptor; na verdade, ambos estão realizando ao mesmo tempo o processo de significação, e por essa razão, a AD utiliza o termo “interlocutor" para designar os polos diante da complexidade do dizer (ORLANDI, 2005).

Ao lançarmos nossos olhares discursivamente sobre a materialidade textual dos pronunciamentos, estamos nos referindo a uma estrutura que envolve sujeito, linguagem e história, levando em conta que a linguagem tem sua materialidade e seu funcionamento baseado na relação estrutura/acontecimento (ORLANDI, 2012, p. 151). A teoria dos discursos entende a língua para além de códigos com significado preestabelecido e estável que pode ser, portanto, decodificável. Desta maneira, não existe repasse de significados e os sentidos são, antes, dinâmicos, instáveis e negociáveis. Logo, múltiplas são as possibilidades de leitura de qualquer material significante - como, por exemplo, os sentidos de política.

Portanto, os sentidos não estão apenas nas palavras, mas na relação com a exterioridade, com o sistema de significação em que o indivíduo se inscreve - formado pela língua, pela cultura, pela ideologia e pelo imaginário -, nas condições em que eles são produzidos e que não dependem somente das intenções dos sujeitos. Fala-se, portanto, da noção de "interdiscurso" (ORLANDI, 2005, p. 30).

Diante de um texto, cabe ao analista de discurso a tarefa de compreender como ele significa, isto é, descobrir quais sentidos o atravessam no intuito de encontrar as regularidades da linguagem em sua produção. $\mathrm{O}$ analista de discurso, portanto, relaciona a linguagem à sua exterioridade e procura mapear as formações discursivas que a compõem, considerando como elas se vinculam às formações ideológicas (ORLANDI, 2005, p. 43-44).

Além de não ser livre de determinações, a produção do discurso é desigualmente distribuída na formação social, já que não é todo mundo que pode interpretar de acordo com sua vontade. Conforme explica Orlandi (2005, p. 10), "há especialistas, há um corpo social a quem se delegam poderes de interpretar (logo de 'atribuir' sentidos), tais como o juiz, o professor, o advogado, o padre etc.”. Ou seja, há modos de se interpretar, sempre "administrados" na história, nunca soltos. Assim, o discurso, como prática social, é o espaço no qual se dá a luta pelo poder e pela univocidade da interpretação, própria a qualquer comunicador, a qualquer falante. Daí o conceito de regularidade discursiva, que permite dar 
conta dos regimes de verdade e das relações poder/saber, ou seja, um padrão de comunicação que se sustenta no tempo, no qual se expressa uma maneira especial de entender, representar e transmitir o sentido da realidade (FOUCAULT, 2009).

Esta análise considera o conceito discursivo de metáfora em que ela é entendida como o deslocamento, o deslize dos sentidos. Ela marca a própria condição de incompletude da linguagem, de forma que nem sujeitos nem sentidos estão completos. Para Orlandi (2007), os enunciados podem apontar para um sentido. Entretanto, existem pontos de deriva que abrem espaço e permitem que outras interpretações sejam possíveis. Sendo assim, todo enunciado é passível de ser interpretado de formas diferentes, variando de acordo com o sujeito e sua relação com a língua e a ideologia. A interpretação configura-se sempre como um ato político, permeado por relações de poder, podendo ser considerada a textualização do político. A direção em que a interpretação acontece, ou seja, o gesto de interpretação, é determinado a partir da historicidade, por meio de mecanismos ideológicos de constituição tanto dos sentidos quanto dos sujeitos - de forma perceptível ou não para eles e/ou seus interlocutores (ORLANDI, 2007a).

\section{OS SENTIDOS DE DILMA ROUSSEFF NO DIA DO TRABALHADOR (2014-2015)}

Para uma compreensão metodológica dos pronunciamentos, os enunciados foram enumerados de acordo com o ano de realização e a ordem de identificação de cada um nos eixos temáticos. Desta forma, os enunciados de 2014 serão identificados com a terminação T14 e os de 2015 com T15. Sendo assim, o primeiro enunciado de 2014 recebe a nomenclatura T14E01, enquanto o primeiro de 2015 é identificado como T15E01. Nesta análise, foram selecionados os enunciados representativos do corpus com o intuito de discutir especificamente a discursividade presente nestas unidades de sentido. Ao todo, foram registrados 75 enunciados, sendo 47 deles no pronunciamento de 2014 e outros 28 em 2015. Considerando-se a imanência do poder assentada na figura do líder de estado, Dilma representa a materialização da institucionalidade em razão do seu lugar de fala e do exercício de força que concebe o estabelecimento da CNRT - prerrogativa do Executivo Federal. O exercício desta posição sujeito pressupõe, de antemão, a identificação política de quem sou, quem somos, além de admitir a existência de um outro, em uma posição adversa. Além disso, há um forte veio de prestação de contas, de leituras econômica e política que pressupõem mecanismos discursivos pelos quais são acionados certos sentidos em detrimento de outros, 
levando-se em consideração que os atos de fala também resultam no silenciamento daqueles que não comparecem à situação de enunciação.

T1402 - Não tenho dúvida, um país que consegue vencer a luta do emprego e do salário nos dias difíceis que a economia internacional atravessa, esse país é capaz de vencer muitos outros desafios.

T1406 - Nosso governo será sempre o governo da defesa dos direitos e das conquistas trabalhistas, um governo que dialoga com os sindicatos e com os movimentos sociais e encontra caminhos para melhorar a vida dos que vivem do suor do seu trabalho.

T14E07 - Neste $1^{\circ}$ de Maio, quero reafirmar, antes de tudo, que é com vocês e para vocês que estamos mudando o Brasil Vocês que estão nas fábricas, nos campos, nas lojas e nos escritórios sabem bem que estamos vencendo a luta mais difícil e mais importante: a luta do emprego e do salário.

T15E02 - O Brasil vive hoje em plena democracia. Temos de nos acostumar as vozes das ruas, aos pleitos dos trabalhadores.

T15E03 - Caberá a nós todos encontrarmos a melhor estratégia e definir os mais eficientes instrumentos para que possamos atingir os nossos objetivos: de fazer o Brasil crescer, aumentando emprego e renda de todos os trabalhadores.

T15E04 - O meu governo tem o compromisso de manter os direitos e as garantias dos trabalhadores.

Considerando-se o aspecto ideológico dos mecanismos discursivos, verifica-se em T14E02 E T14E07 apropriação de alguns sentidos em disputa como "mudança", e a proposição de outros, como "luta". Em 2015, ocorre o oposto talvez em função do cenário político de desaprovação da presidente e a crescente pressão da oposição no Legislativo Federal e nas ruas, com protestos e panelaços. Estes lexemas e seus derivativos desaparecem e dão espaço a um discurso de afirmação econômica e democrática em 2014, talvez em função de uma leitura do governo que privilegia a defesa das instituições em detrimento de sentidos antes destacados.

No eixo de construção de imagem, Rousseff trabalha questões que remetem a sua capacidade de gestão e à identidade do brasileiro, este último sempre ligado ao sistema produtivo pela questão do emprego e do salário. Em ambos os casos, Dilma recorre aos ideários de democracia e economia para nortear os conjuntos de ações do governo - tanto aquelas que estavam em transformação no momento do pronunciamento, como as propostas e assumidas pelo governo para o futuro. Em T14E07, Dilma retoma um ideário de mudança que aparentemente está presente na memória discursiva do brasileiro, referente ao fato de o 
Partido dos Trabalhadores ter assumido o governo pela primeira vez em 2002. No caso, são acionados os discursos que atravessam esta perspectiva histórica.

A presidente busca proximidade com o trabalhador na medida em que demonstra, por mecanismo de alteridade, conhecimento e capacidade de diálogo sobre as condições de trabalho do brasileiro e seus principais desafios, entre eles as questões do emprego e do salário. Dilma manifesta otimismo sobre estas pautas em 2014 e reconhece o cenário econômico negativo - o que também ocorre em 2015, embora não haja nenhum otimismo por parte da presidente. Ainda assim, ela retoma novamente a perspectiva otimista quando reforça sentidos a respeito da superação aos desafios postos. Verifica-se abaixo essa correlação no enunciado T14E12, considerando-se que não há correspondente em 2015.

T14E12 - É com esse sentimento que garanto a vocês que temos força para continuar na luta pelas reformas mais profundas que a sociedade brasileira tanto precisa e tanto reclama: nas reformas para aperfeiçoar a política, para combater a corrupção, para aumentar a transparência, para fortalecer a economia e para melhorar a qualidade dos serviços públicos.

T14E04 - Nosso governo tem o signo da mudança e, junto com vocês, vamos continuar fazendo todas as mudanças que forem necessárias para melhorar a vida dos brasileiros, especialmente dos mais pobres e da classe média;

T14E13 - Se hoje encontramos um obstáculo, recomeçamos mais fortes amanhã, porque para mim as dificuldades são fonte de energia_e não de desânimo. Se nem tudo ocorre no tempo previsto e desejado, isso é motivo para acumular mais forças, para seguir adiante e, em seguida, mudar mais rápido. É assim que se vence as dificuldades, é assim que se vai em frente

Em T14E12, com um discurso dramático, a presidente aproxima-se do público/eleitor demonstrando sensibilidade e confiança. Neste aspecto, a expressão "temos força para continuar" faz referência clara à sequência de procedimentos que na sua visão estão sendo realizados com sucesso, embora demonstre que o sentido de mudança proposto pelo governo está em disputa. Rousseff reconhece novamente as lutas da sociedade brasileira contra a corrupção, de aperfeiçoamento democrático, para o aumento da transparência, de fortalecimento da economia e para a melhoria dos serviços públicos. Vale dizer que essas pautas eventualmente retornam ao centro da discussão política no país como problemas não resolvidos, algo que pode ser entendido como uma resposta do mecanismo de latência para sentidos presentes na interação entre o indivíduo e estrutura - no caso, o cidadão e o Estado. O que ocorre, portanto, é um reconhecimento de problemas que carecem de solução pelo seu exato oposto. 
A questão da mudança é tratada de outra forma em T14E04. A presidente atribui o sentido de transformação ao seu governo quando afirma que possuem "o signo da mudança". No entanto, considerando-se que o sentido de mudança está em constante utilização pelas correntes políticas que disputam o poder no país, o lugar de fala de onde Dilma se posiciona é ambíguo. Não há nada que deslegitime a proposição de mudança do governo, embora haja uma contradição discursiva que reside no fato de o seu governo não ter supostamente solucionado os problemas em uma oportunidade que já lhe foi consentida. Dilma reforça os sentidos de heroísmo e bravura alinhados ao seu perfil ao longo de sua trajetória política em T14E13. Mais tarde, nas Eleições de 2014, este aspecto discursivo da imagem de Dilma é incorporado à sua campanha pelo jingle "Dilma Coração Valente".

Percebe-se nestes discursos destacados a mobilização de sentidos que remetem à mudança e à luta com certo grau de otimismo. É desta forma que Dilma atribui sentidos ao seu governo e, além disso, discute a condição política, econômica e de direitos do trabalhador, em um cenário no qual o governo possui aparente capacidade propositiva e de gestão, com legitimidade para assumir tais posições discursivas. Em 2015, no entanto, o pronunciamento é endurecido pela temática econômica e de proposições do governo à Câmara, com endosso da necessidade de diálogo com a sociedade, logo depois de uma vitória acirrada de Dilma Rousseff nas urnas e a subsequente ofensiva de uma oposição inconformada com a derrota eleitoral.

No eixo de análise Ataque aos Adversários, é perceptível a mudança no discurso de Dilma entre os pronunciamentos de 2014 e 2015. Se em 2014 foram empregados numerosos lexemas que remetiam a necessidade de "mudança" e "luta", no ano de 2015 essas recorrências cessaram e deram espaço à tentativa de estabelecer diálogo com diversos setores da sociedade civil.

T14E19 - Continuar com as mudanças significa também continuar lutando contra todo tipo de dificuldades e incompreensões, porque mudar não é fácil, e um governo de mudança encontra todo tipo de adversários, que querem manter seus privilégios e as injustiças do passado, mas nós não nos intimidamos;

T14E20 - Algumas pessoas reclamam que o nosso salário-mínimo tem crescido mais do que devia.

T14E21 - Para eles, um salário-mínimo melhor não significa mais bem-estar para o trabalhador e sua família, dizem que a valorização do saláriomínimo é um erro do governo e, por isso, defendem a adoção de medidas duras, sempre contra os trabalhadores. 
Dilma não nomeia seus adversários de maneira direta em T14E19, mas é possível percebê-los no discurso. A presidente elipsa suas identidades, mas deixa evidente que eles são um entrave para a "mudança" proposta pelo seu governo, as quais são retomadas em praticamente todas as tomadas de fala. O que significa dizer que vão de encontro aos ganhos reais de renda do trabalhador e, desta forma, também são seus adversários políticos. Este tipo de discurso está impregnado de mecanismos ideológicos em função da composição de uma narrativa que ilustra a perspectiva da presidente em relação ao trabalhador, obviamente diferente do ponto de vista dos adversários.

A presidente aciona sentidos políticos progressistas na medida em que defende a diminuição da desigualdade e a necessidade de resgatar a dívida social do país com os mais pobres, conforme se observa em T14E20 e T14E21. A elipse de identidade dos sujeitos da frase abre uma lacuna interpretativa a respeito de quem seriam os "adversários", aqueles "reclamam" e dizem que "a valorização do salário mínimo é um erro". Esses discursos vão de encontro ao ideário neoliberal de diminuição do estado e distribuição economicista das oportunidades. No entanto, Dilma trata da desregulamentação do trabalho e da desvalorização do salário mínimo como algumas das proposições do campo adversário que devem ser combatidas. Entende-se que as portadoras deste discurso sejam, em uma concepção estrutural, as elites financeiras e políticas do país. O lugar de fala do governo como gestor, preocupado com as condições trabalhistas, é reiterado quando a presidente rechaça o arrocho salarial e medidas duras contra o trabalhador, conforme se vê em T14E05:

T14E05 - Nosso governo nunca será o governo do arrocho salarial, nem o governo da mão dura contra o trabalhador.

Este discurso que identifica Dilma, seu governo e o trabalhador pela diferença de propósitos sugerida no âmbito dos sentidos adversos perde credibilidade na medida em que o governo edita uma política econômica de austeridade e se distancia dos movimentos sociais, em contradição às enunciações feitas anteriormente. $\mathrm{O}$ silenciamento das questões relacionadas à "mudança" e à "luta" em 2015 talvez sejam justificados pela incoerência discursiva que emerge na prática social. Não obstante, as taxas de aprovação do governo diminuem e a ofensiva da oposição ganha força, o que determinou a escolha de um pronunciamento pelas redes sociais.

As percepções a respeito dos discursos que atravessam aspectos políticos são evidenciadas quando se observa o terceiro e último eixo deste trabalho, no qual elencamos os 
Temas Políticos. De forma genérica, podemos afirmar que o tom de ambos os pronunciamentos é técnico e de prestação de contas e, vez ou outra, assume um caráter personalista. Isto pode ser evidenciado pelo uso de pronomes possessivos que eventualmente irrompem na fala da presidente, os quais se repetem com mais frequência em 2015. Contudo, destaca-se o fato de Dilma ter silenciado a questão da corrupção no pronunciamento de 2015, no qual foram enfatizadas as ações do governo durante os três mandatos de governo petista.

T14E33 - Quero reafirmar o compromisso do meu governo no combate incessante e implacável à corrupção.

T14E11 - Temos credibilidade política para dizer isso. Nos últimos 11 anos, tivemos o mais longo período de inflação baixa da história brasileira.

T15E10 - Por isso o salário mínimo cresceu 14,8\% acima da inflação em meu primeiro mandato.

T15E18 - Nos últimos 13 anos, o Dia do Trabalhador tem sido uma data para avaliar e celebrar as vitórias da classe trabalhadora. A valorização do salário mínimo é uma das maiores conquistas deste período.

Em T14E33, Dilma reitera por meio do prefixo "re-" a sua disposição em investigar a corrupção em discursos anteriores ao pronunciamento, tendo em vista que esta é a primeira menção ao assunto. Ou seja, Rousseff aciona a memória discursiva a respeito de algo já dito e que é deliberadamente escolhido em defesa de sua posição a respeito da corrupção. O prefixo “in-”, por sua vez, demonstra, o caráter de perene do processo de investigação. Em T14E11 fica evidente a defesa do governo e dos governos anteriores quando a memória discursiva é acionada. A presidente aciona sentidos a respeito dos governos anteriores de Lula e de seu mandato como presidente quando fala sobre os "últimos 11 anos" e associa este período ao "mais longo período de inflação baixa da história brasileira".

Este tipo de prestação de contas também pode ser observado em T15E10 e T15E18, de uma forma mais personalizada pelo fato de a presidente associar diretamente a questão do crescimento do salário mínimo ao seu mandato. Em uma opção discursiva clara pela prestação de contas e em função de uma imagem pública de gestora, Dilma frequentemente dirige-se aos cidadãos como "trabalhadores e trabalhadoras". Em quatro momentos, a presidente referese a eles ativando o sentido de que são sujeitos de direito, ao contrário do que acontece quando se aproxima informalmente do público/eleitor com a expressão "meus amigos e minhas amigas". 


\section{CONSIDERAÇÕES FINAIS}

A estratégia de comunicação adotada pelo Governo Federal, desde a transição do primeiro para o segundo mandato de Dilma Rousseff, sugere um esforço no sentido de evitar a superexposição da presidente em um momento em que o país atravessa dificuldades econômicas e quando o governo inicia uma postura de arrocho fiscal e de corte de investimentos públicos. Essa perspectiva começa a ficar perceptível antes mesmo da popularidade da presidente entrar em crise acentuada em 2015. Ela pode ser verificada já no final de 2014, quando a presidente termina o primeiro mandato e decide não se pronunciar em CNRT por ocasião do fechamento do ano, o que havia sido feito sucessivamente nos anos de 2011 a 2013. A mudança na estratégia de deslocar os pronunciamentos da mídia massiva - no caso a televisão, amplamente utilizada no primeiro mandato quando se tinha altos índices de popularidade - para as mídias digitais já apontava para a fragilidade do governo que, com perda da base aliada no Congresso, forte oposição da grande imprensa e altos índices de rejeição, acabou sofrendo um processo de impeachment em 2016.

Evidencia-se que a finalidade dos pronunciamentos em CNRT tem sido, primordialmente, a construção publicitária da imagem do governo, mais do que a prestação de contas. Em outros termos: o importante, de fato, não é prestar contas do ano transcorrido ou justificar ações, e sim construir uma imagem estratégica e positiva do governo. As transformações discursivas nos pronunciamentos e as mudanças no cenário político (e da mídia utilizada) sinalizam para uma percepção da relevância da visibilidade midiática como instrumento cada vez mais estratégico de acúmulo de capital político (ou de tentativa de diminuição de sua perda). A análise da mudança de mídia e de formato sinalizava também para transformações que estão ocorrendo de forma bem acelerada nos hábitos de consumo de mídia no Brasil, o que interfere na visibilidade dos atores políticos. Hoje, há uma confluência das mídias massivas e mídias digitais.

Neste âmbito, a análise do discurso contribuiu para um entendimento dos mecanismos pelos quais foram articulados os atos de fala da presidente Dilma Rousseff. É perceptível que a presidente tem consciência de que seu lugar de fala não a autoriza a se comunicar apenas com o trabalhador. Seus discursos em CNRT atravessam todo corpo social e alcançam atores políticos e econômicos. Logo, os pronunciamentos não podem ser entendidos como uma ferramenta puramente classista, dirigida somente aos trabalhadores, mas discursos 
vocalizados para além dos grupos sociais com quem se comunica. Portanto, são produzidos sentidos verticais quando se pensa na relação da presidente com os cidadãos, e em relações horizontais, com players econômicos e políticos, dos quais o governo em alguma medida depende.

A partir da subdivisão temática, foi possível discutir a engrenagem de mecanismos ideológicos, de memória discursiva, elipses e silenciamentos identificados nos enunciados selecionados. Vale dizer que quando se opta por divulgar o discurso presidencial através de um meio com menor abrangência e que atinge, principalmente, seguidores a apoiadores do governo, como é o caso da internet, fica evidente o caráter primordialmente publicitário dos pronunciamentos, voltados para a consolidação da imagem governamental entre aqueles em que certamente a adesão ao que é dito será maior.

Enquanto nos pronunciamentos do primeiro mandato a imagem governamental foi projetada em termos de sua proximidade com os mais pobres, de seu comprometimento com políticas sociais e com a ampliação e o melhoramento dos serviços públicos, em maio de 2015 a projeção da imagem do governo se deu em termos de sua disposição para o diálogo, de sua postura de respeito à democracia e às críticas que recebeu da sociedade, em uma atitude que se adequa ao momento de crise nos índices de aprovação popular.

A comparação entre os pronunciamentos realizados em 2014 (via CNRT) com os pronunciamentos veiculado em 2015 (via internet) também revelou o silenciamento, entre o primeiro pronunciamento e o segundo, de formações discursivas como "mudança", "luta" e “corrupção - o que sugeriu o intento de não confrontar o discurso da presidente com a percepção gradativamente mais negativa que a população constituía a respeito dela em um momento de pressão da oposição, desaquecimento econômico, aumento da inflação e escândalos políticos no seio do governo. $\mathrm{O}$ estudo, ao apontar para a fragilidade da então presidente Dilma e sinalizar para um modelo híbrido de consumo de mídia, já antecipa mudanças importantes que se operaram no país desde 2015.

\section{REFERÊNCIAS}

AGGIO, Camilo de Oliveira. 2011. "Internet, Eleições e Participação: Questões-chave acerca da participação e do ativismo nos estudos em campanhas Online". In: GOMES, Wilson; MAIA, Rousiley \& MARQUES, Francisco Jamil (Orgs). Internet e Participação Política no Brasil. Porto Alegre: Editora Sulina, p. 175-196. 
BRASIL, Presidência da República. Secretaria de Comunicação Social. Pesquisa Brasileira de Mídia 2015: hábitos de consumo de mídia pela população brasileira. Brasília: Secom, 2014.

DUARTE, Jorge (Org.). Comunicação Pública: Estado, Mercado, Sociedade e Interesse Público. São Paulo: Atlas, 2007.

FOUCAULT, Michel. A arqueologia do saber. Rio de Janeiro: Forense Universitária, 2009.

GOMES, Wilson. As transformações da política na era da comunicação de massa. São Paulo: Paulus, 2004.

GOMES, Wilson. 2011. "Participação política Online: questões e hipóteses de trabalho". In: GOMES, Wilson; MAIA, Rousiley \& MARQUES, Francisco Jamil (Orgs). Internet e Participação Política no Brasil. Porto Alegre: Editora Sulina, p. 19-46.

JENKINS, Henry. Cultura da Convergência. São Paulo: Aleph, 2009.

LIMA, Ismar Borges; SILVA, Noêmia Félix da. Segmentação, Esfera Pública Virtural e Horizontalidade Dialógica da Comunicação nas Redes Sociais. In: Fragmentos de Cultura (Online). V.20, p.191-206, 2010.

MIGUEL, Luis Felipe. Capital político e carreira eleitoral: algumas variáveis na eleição para o Congresso Brasileiro. In: Revista de Sociologia e Política (Online). V.20, p.115-134, 2003.

ORLANDI, Eni Puccinelli. Análise de Discurso: Princípios e Procedimentos. São Paulo: Pontes Editores, 2005.

As formas do silêncio: no movimento dos sentidos. Campinas, SP: Editora da UNICAMP, 2007.

Interpretação: Autoria, leitura e efeitos do trabalho simbólico. Campinas, SP: Editora Pontes, 2007a.

Discurso em análise: Sujeito, Sentido, Ideologia. 2. ed. Campinas, SP: Editora Pontes Editores, 2012.

RODRIGUES, Adriano Duarte. Estratégias de comunicação. Lisboa: Editorial Presença, 1990.

SANTOS, Wanderley Guilherme dos. A democracia impedida: o Brasil no século XXI. Rio de Janeiro: FGV Editora, 2017.

SOUZA, Jessé de. A radiografia do golpe. Rio de Janeiro: Editora LeYa, 2016.

THOMPSON, John Brookshire. A nova visibilidade. In: Matrizes. V.1, n. 2, p.15-38, 2008. 


\section{Luiz Ademir de Oliveira}

Doutor e Mestre em Ciência Política pelo IUPERJ, mestre em Comunicação Social pela UFMG, é docente e pesquisador do Programa de Pós-Graduação em Comunicação Social (PPGCOM) da UFJF e do Curso de Comunicação Social - Jornalismo da UFSJ.

Gustavo Fernandes Paravizo Mira

Mestre em Comunicação Social pelo Programa de Pós-Graduação em Comunicação Social (PPGCOM) da UFJF e Graduado em Comunicação Social - Jornalismo pela UFV.

Paulo Roberto Figueira Leal

Mestre e Doutor em Ciência Política pelo IUPERJ, docente e pesquisador do Programa de Pós-Graduação em Comunicação Social (PPGCOM) da Universidade Federal de Juiz de Fora (UFJF).

\section{@ $\odot \odot$}

Esta obra está licenciado com uma Licença

Creative Commons Atribuição-NãoComercial-CompartilhaIgual 4.0 Internacional 